\title{
TELECAD COURSE ONLINE AND EVALUATION PROCEDURE
}

\author{
Anna Grabowska, $\mathrm{PhD}$ \\ Gdansk University of Technology, G. Narutowicza 11/12, 80-952 Gdansk, Poland. E-mail: \\ blanka@pg.gda.pl
}

Abstract: In the article the Learning Management System TeleCAD (Teleworkers Training for CAD Systems' Users, Leonardo da Vinci, 1998-2001) is presented. The system background is described. Usability of the system is presented within CURE project (Research Framework Programme 5, 20032005). Evaluation procedure for online courses is described on a basis of experiences in EMDEL project (European Model for Distance Education and Learning, Leonardo da Vinci, 2001-2004).

Key words: Learning Management System; AutoCAD; telework; evaluation.

\section{TELECAD - WHAT IS ALL ABOUT}

TeleCAD (Teleworkers Training for CAD Systems' Users) is a course of AutoCAD and teleworking basics. Actually the course is delivered in distance mode as an Internet based course.

The project TeleCAD was co-financed by European Union Leonardo da Vinci Programme (1998-2001). It was developed in a consortium of six foreign institutions from four countries: Greece, Finland, Italy and Poland.

The idea of the course evolved from the AutoCAD course delivered on Civil Engineering Department at Gdansk University of Technology. During the course students are expected to prepare a series of drawings, at different levels of complication. For the purpose of final assessment students had to prepare a drawing that used all introduced techniques. 
In the past the AutoCAD course was delivered in a traditional mode - as lectures and activities in computer laboratory. In order to reduce the load in lecture rooms the idea to convert the course to the distance mode was born.

In 1998 a few students took part in an experimental distant course. They were given printed course materials and were supposed to contact the teacher using e-mail only. Both consultations and final assignment submission was done by e-mail. All students succeeded in finishing the course. After the course there was an extensive study of experimental course results. More than 60 students took part in the experimental AutoCAD courses delivered by Distance Education Centre at Gdansk University of Technology (DECTUG) together with Civil Engineering Department in ODL mode. Both students and the teacher were satisfied with the course and experiences gathered were used during the TeleCAD project application preparation.

As a result of Leonardo da Vinci project students have for their disposal course materials consisting of 10 modules covering basics of drawing in AutoCAD. Every module includes a set of tasks that should be performed by students, with description of appropriate solution. The course materials are prepared as HTML pages to be acquired by the WWW or from the CDROM. Polish version of the materials is also available in a printed form. The TeleCAD course incorporates a module about basics of teleworking. Current technology and methodology of teleworking is presented to the students, and an example of our system is used for exercise. Students are supposed to prepare a project in groups. They should prepare the project in co-operation between each other, using the Task Management Module of the system as a platform for project design. The final assignment of the course is a drawing prepared by a student and sent by mail to the tutor. To prove that the student actually was an author of the drawing, he may be asked to make some changes to the drawing in the presence of the tutor. The whole course is performed in a blended mode. There are two face to face meetings: $1^{\text {st }}$ for teaching how to use TeleCAD and $2^{\text {nd }}$ for examination purpose.

While the method of TeleCAD course delivery was discussed several WBT platforms were considered to be used. DECTUG was involved in DE Phare projects with different platforms e.g. WebCT, Learning Space, First Class. They differ in offered capabilities and price. Most of them are oriented towards course materials delivery. They provide user authentication, customisable start pages, user homepages preparation tools etc. For example First Class focuses only on student-tutor communication. Some of the platforms offer tools for organising chat rooms or computer conferences. The main drawback of available packages is lack of good monitoring system. What is also very important, there is very little support for manager of the distance teaching institution. In most platforms there is 
no support for the course evaluation or tutors' reports. All communication between the tutor and course manager must be performed outside the system.

The system should also organise the co-operation between course developers. This includes communication, file sharing and project management tools. The system will also play a role of the course delivery platform. It will provide students management, support for tutors, communication environment and assessment tools. The main stress should be put on the management of Internet based ODL solution. The course manager, who is usually responsible for many virtual classes, should have information about students' and tutors' activities. He (she) should know if a tutor's activities are relevant to students' needs. This includes answering students' questions fast and in satisfying degree, preparing FAQs (Frequently Asked Questions), preparing and marking Tutor Marked Assignments (TMA's) etc.

Students' progress is a very important issue in distance education. There are a few ways to monitor it with a web based environment. Students perform self-assessment tests and TMAs that give insight to their progress. System may monitor students' activity on discussion lists, access to course material web pages, FAQ lists etc. The last but not least is students' own opinion about their own progress reported by questionnaires.

It is not certain that all above techniques give satisfying information about students' and tutors' performance. However, they give some indication when somebody may have problems. In such situation the manager has opportunity to investigate the issue personally. Without any monitoring support, the manager is incapable of assisting many people simultaneously.

The system is divided into several independent parts and consists of course delivery subsystem, course management and monitoring subsystem and personal information database subsystem.

The subsystems share the tools, they have a common database of users and a common user interface. They may be however used separately without the second one installed.

The system is designed in thin client-server architecture. The server is based on the SQL engine (currently MySQL) and a web server capable of running PHP3 scripts (apache server with mod_php3 extension). The whole system logic is contained in the PHP3 scripts. The hardware platform for the system is a PC computer with Linux operating system. The client is a graphical web browser with no additional software needed. This architecture was chosen to ensure ability to work from any place in the Internet. Taking into account the actual parameters of Internet connections, it was decided to reduce the amount of data at the cost of user interface of the system. TeleCAD system tools are shown in Table 1. 
Table 1. The prototype TeleCAD course tools

\begin{tabular}{ll}
\hline Course Information: & Requirements \\
& Timetable \\
& Staff Information \\
& Students list \\
& Announcements \\
& FAQ \\
\hline Course Materials & Guide for learner \\
& AutoCAD handbook online \\
& Teleworking survey online \\
& Library of drawings \\
& Library of links \\
\hline Assignments & Requirements and forms and deadlines for \\
& assessments \\
& Class book \\
& The quiz \\
\hline Communication & Bulletin Board \\
& Discussion list \\
& E-mail \\
\hline
\end{tabular}

\section{TELECAD USABILITY AND EVALUATION}

The proposed system TeleCAD covers educational needs of students and academic teachers in the field of AutoCAD and telework subject. In the Table 2 there is a list of TeleCAD environment usage (2000-2002).

Table 2. Usage of TeleCAD from 2000 to 2002

\begin{tabular}{ll}
\hline TeleCAD implementation & Number of users \\
\hline Pilot international (2000/2001) & 89 \\
Pilot PL (2000/2001) & 35 \\
TeleCAD exam in (sem. 2, 2000/2001) & 240 \\
TeleCAD exam in (sem. 4, 2000/2001) & 166 \\
TeleCAD extra mural (sem. 4, 2000/2001) & 62 \\
TeleCAD extra mural (sem. 3, 2001/2002) & 24 \\
TeleCAD extra mural (sem. 4, 2001/2002) & 40 \\
TeleCAD exam in (sem. 2, 2001/2002) & 259 \\
TeleCAD in summer 2002 & 4 \\
\hline
\end{tabular}

The most significant achievement seems to be offering the course for postgraduate MSc students from Civil Engineering Department in the academic year 2003/2004 in CURE project (Centre for Urban Construction and Rehabilitation: Technology Transfer, Research and Education, Research Framework Programme 5, 2002-2005). 
There is another aspect of distance education which could not be neglected. It is quality of distance education courses. Quality issues are addresses in EMDEL project (http://www.emdel.org/).

The main goal of the project EMDEL is development of an European Teletraining System which, from what already has been produced, could immediately start a process of co-operation at the level of production and organisation of distance training services. This approach should bring to the reduction of costs, the harmonisation of local systems and the rapid increase of the offer of formative courses.

The main objectives of the project are following:

- Production of an on-line catalogue "Showcase of Distance Learning Modules".

- Production and share of a basic software programme for the assessment of customer satisfaction and quality of Distance Learning Modules.

- Exchange of the best Distance Learning Modules.

- Virtual mobility through on-line utilization of Distance Learning Modules installed on the servers of the partners' net. It should enable to utilize of distance training products in original language by a person living in a partner country without an action of postproduction. Local services of support should be assured in the original language).

- Dissemination, through the presentation of a model of realization, of a European Teletraining Network to demonstrate the concrete possibilities of construction, starting from an existent distance training system based locally but with transnational connections. The dissemination also aims at extending the number of agencies of distance training, which want to co-operate for the maintenance of the catalogue and for the increase of the exchange of products.

The project moves from the results achieved in previous projects by partner countries in the field of the European financing. The Regione Toscana, within the frame of activities provided by the Fondo Sociale Europeo, has given birth to a Regional System of Teletraining (Trio Project, http://www.progettotrio.it) and to the production of didactic contents for Distance Learning chiefly addressed to apprentices, drop out young people, workers, managers of small enterprises, besides old people. Also the partners' experience has lead to the creation of distance learning models and, particularly, to the production and evaluation of materials which can be used in High Training as well as in the trainers' training.

The project has started from collecting information about partners' institutions and their offer in the subject of Distance Learning Modules.

The evaluation procedure and the questionnaires were prepared by University of Liege from Belgium (Table 3). 
Details of TeleCAD course evaluation will be presented during the panel discussion.

Table 3. Quality and Customer Satisfaction Table

\begin{tabular}{ll}
\hline 1. & Expert's assessment \\
I. Content \\
II. Activities \\
III. Evaluation \\
IV. Technical aspects \\
V. Aesthetics and multimedia \\
VI. Mode of usings \\
VII. Mode of using \\
Tutor's assessement \\
I. Content \\
II. Activities \\
III. Evaluation \\
IV. Technical aspects \\
V. Aesthetics \\
VI. Mode of using \\
Customers' Satisfaction \\
I. Number of responses: ... \\
II. Overall impression \\
III. Contents \\
IV. Activities \\
V. Evaluation \\
VI. Navigation, technical design and ergonomics \\
VII. Tutoring \\
Customers' satisfaction rating is quantitative. For each of the six items a graph in \\
the form of a line is drawn. One end of this line is labelled "Poor", the other, \\
"Excellent". The rank is based on the average rating of each item. \\
Impact on customers \\
Percentage of students who dropped the course (if any) \\
Rate of successful outcome (if any) \\
4.
\end{tabular}

\section{REFERENCES}

Grabowska Anna (2001). Model for Distance Eduaction System in LAN and WAN. 150 pp. $\mathrm{PhD}$ thesis /2001.11.20/. Gdansk University of Technology, Faculty of Electronics, Telecommunications and Informatics.

Grabowska Anna (2003). Web Based Training system TeleCAD (Teleworkers training for CAD system users). Global Engineer: Education and Training for Mobility. SEFI Conference 2003. Porto. Portugal, 7-10 September 2003. Ed: Alfredo Soeiro, Carlos Oliveira Universidade do Porto Faculdade de Engenharia, Porto 2003, s. 282-287.

Grabowska Anna (2003). Searching for evaluation procedures for Web based courses . cases from EU projects. 12th EDEN Annual Conference. The Quality Dialogue. Integrating Quality Cultures in Flexible, Distance and eLearning. Rhodos. Greece, 15-18 June 2003. Ed: dr Andras Szucs, dr Erwin Wagner, dr Costas Tsolakidis, Rhodos 2003, s. 226-231. 
http://www.dec.pg.gda.pl/dec/index.php?id=telecad_en TeleCAD course online http://www.emdel.odrg/ EMDEL project main page http://www.pg.gda.pl/cure/ CURE project main page 